\title{
Research Data Collection in Challenging Environments: Barriers to Studying the Performance of Zimbabwe's Parliamentary Constituency Information Centres (PCICs)
}

\section{Isaiah Munyoro}

Post-Doctoral Research Fellow, Department of Information Science, University of South Africa (UNISA), Pretoria; and Director of Library Services, Parliament of Zimbabwe, Harare

\begin{abstract}
This article describes and analyses data collection challenges encountered in the course of research into the performance of Zimbabwe's Parliamentary Constituency Information Centres (PCICs). During collection of data on the work of PCICs in various constituencies across the country, many of them rural, the following challenges were encountered: low response rates; unreliable road access; unsuitable physical locations of PCICs, including politicised locations; political and legal restrictions; time management and financial challenges; and religious and cultural barriers. The article concludes that researchers planning data collection in developing-world environments must be cognizant of the particular challenges these environments may pose, while at the same time contending with challenges that all researchers, in both developed and developing worlds, face, such as the need ensure strong connections with people based in the local environments in which data collection is to take place.
\end{abstract}

\section{Keywords}

research, data collection challenges, qualitative research, politics, law, culture, religion, developing world, Zimbabwe, Parliamentary Constituency Information Centres (PCICs)

DOI: $\underline{\text { https://doi.org/10.23962/10539/26111 }}$

\section{Recommended citation}

Munyoro, I. (2018). Research data collection in challenging environments: Barriers to studying the performance of Zimbabwe's Parliamentary Constituency Information Centres. The African Journal of Information and Communication (AJIC), 21, 81-95. https://doi.org/10.23962/10539/26111

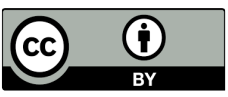

This article is licensed under a Creative Commons Attribution 4.0 International (CC BY 4.0) licence: http://creativecommons.org/licenses/by/4.0 


\section{Introduction}

UNESCO (2009) has highlighted problems of research data collection due to cultural practices in certain settings. Many cultures are reserved, thereby militating against participation in research, even when the research has developmental objectives, while other cultures are open, providing researchers with information that can then potentially positively contribute to development. This article highlights some of the data collection challenges I faced as a researcher during data collection on the performance of Zimbabwe's Parliamentary Constituency Information Centres (PCICs).

In Zimbabwe, PCICs are, as their name suggests, entities that aim to provide information on the workings of Parliament. The reforms of the Parliament of Zimbabwe, which started in 1997 and continued into the 2000s, included a decision to reform its information services. PCICs were set up in all 120 of the constituencies that existed at the time of the Fifth Parliament, from 2000 to 2005. The idea behind the establishment of PCICs was twofold: to provide public access to Parliamentgenerated information; and to act as a platform for public participation in Parliament's activities.

The PCICs have faced numerous challenges, both operational and administrative, since their inception, and several evaluations and studies have been conducted in an effort to find ways of improving their operations (see, for example, De Vrieze \& Murupa, 2012). De Vrieze and Murupa (2012), during their visits to collect data for evaluation of the operation of the PCICs, found that political partisanship was retarding public participation at the centres. They recommended education and awareness campaigns to improve PCIC operations. They also noted lack of clear understanding of the PCIC project's objectives, as implemented by the central government and development partners (De Vrieze \& Murupa, 2012).

It was during my study of the PCICs that I encountered the particular set of data collection challenges that are the focus of this article. As is outlined below, two of the key problems faced in seeking to interact with constituents targeted by PCICs are also problems faced by the Centres themselves in their interactions with citizens. Constituents' lack of awareness of the functions of the PCICs, and their mistrust of the Centres due to their apparent political affiliations, is indeed a hindrance to researchers seeking to study the performance of the PCICs.

More fundamentally, these problems would appear to be undermining the ability of the PCICs to fulfil their important role as conduits between ordinary Zimbabweans and the workings of their elected MPs in the national Parliament. It would seem that there is, thus, a need to educate MPs and citizens on the roles of the PCICs, and to extensively market the PCIC project, so that both MPs and constituents are aware of, and support, the objectives of the initiative. 
This article is not, however, focused on the performance of the PCICs, but, rather, on the difficulties encountered in seeking to collect research data on PCICs'performance.

\section{Literature review}

\section{Research data collection challenges}

It is widely accepted that researchers must make known the shortcomings and challenges experienced in their data collection (see Lutabingwa \& Nethonzhe, 2006). Silverman (2007) warns that in political contexts, researchers must exercise caution when collecting data. Gill, Stewart, Treasure, and Chadwick (2008) focus on the need for researchers to secure free access to research sites. Bailey (2007) focuses on the need for researchers to be as free as possible from constraints when using qualitative research methods such as interviews and focus groups. (As is explained later, interviewing was made difficult when a PCIC was located in premises that had political associations, and focus groups could not be convened to collect data because of challenges posed by the Public Order and Security Act (POSA).)

Cole and Knowles (2001) focus on participants' literacy, and how the language of interview questions and survey instruments can have an impact on data collection. Participants' literacy may influence their understanding of questions in a data collection instrument, consequently impacting the data collection process. Analysing challenges faced by $\mathrm{PhD}$ students, Dearnley (2005) found that researchers encounter numerous obstacles. Peersman (2014) has also written about the time and financial costs associated with accessing remote areas.

For example, for my PCIC study, travelling long distances was required to collect data in rural constituents, and there were accommodation, transport and other related costs. Other data collection challenges that one can face include time limitations, and concern over being criticised regarding the significance, methods, or conclusions of one's research (Creswell, 2003; 2009). The qualitative research approach places pressure and scrutiny on the "the researcher's ability to systematically demonstrate transparency and accountability throughout the whole research process" (Davies \& Hughes, 2014, p. 12).

\section{Data collection challenges in the developing world}

A number of studies have looked at the degree to which research in the developing world faces challenges that are more pronounced, or different, than for research in the developed world. According to Altshuld and Witkin (2000), challenges of data collection in developing countries include: lack of appreciation of the importance of data collection as an activity, mixed with a general cultural ethos of not sharing personal information with outsiders; remote and thinly populated areas, posing logistical as well as technical problems, e.g., for application of area sampling; infrastructural deficiencies, including poor transport networks, roads, and telecommunication networks; and lack of political and administrative support for autonomous research. 
Bulmer and Warwick (1983) argue that in developing-world research contexts, data collection challenges are not necessarily unique, but rather the challenges are more prevalent and severe than in the developed world. Bulmer and Warwick found that in the US, for instance, the number of respondents who simply did not understand the survey was less than $1 \%$ of a total sample, while in rural areas of some developing countries the figure might be closer to $10 \%$ or $15 \%$.

Reflecting on research data collection challenges in the Caribbean, Busby (2003) found a strong feeling in rural communities that they are different from urban communities, and that they have special qualities not found in the cities. Relationships in rural areas are seen as personal and enduring; unlimited and unspecified in their demands and imbued with a strong sense of loyalty not only to friends and relatives, but to the community and its members. Particularly in many smaller communities, there is a community conception of being part of "the extended family". During a study of South African parliamentary information services and the role of parliamentary libraries, Mostert (2004, p. 193) encountered a major problem of non-responsiveness from respondents.

Speaking from the perspective of an experienced developing-country researcher, Caballero of Johns Hopkins University takes the position that "in many cases, we are in a pre-cultural stage" (Caballero, quoted in NRC, 2014). Caballero argues that in many developing countries, a lack of resources and expertise results in weak research regulation and an increasing reliance on private-sector research support that does not comply with the same kinds of rigorous frameworks that most developed-world researchers are accustomed to (Caballero, paraphrased in NRC, 2014).

In almost all data collection matters, researchers in developing countries face different sets of problems as compared to researchers in developed-world contexts. Elahi (2008), in a study data collection problems in Pakistan's public institutions, identified both internal problems, such as organisational set-up, lack of resources and infrastructure or operational inadequacies, and external problems related to low literacy ratios and lack of awareness of the need for research among potential respondents. Such difficulties can be expected in most developing countries.

\section{Data collection challenges in Zimbabwe}

During the process of data collection in constituencies dominated by political party groups and religious apostolic followers in Zimbabwe, Machingura (2014) encountered resistance of political party membership from political subgroups, and from women and girls because their religious doctrine does not permit them to discuss issues with perceived strangers and researchers.

Feltoe and Maguranyanga (2015) found that data collection challenges in Zimbabwe are more pronounced in rural areas than in urban constituencies, where respondents 
feel freer to volunteer information. Maguranya (2011) argues that data collection challenges in Zimbabwe's rural areas do not develop in a vacuum, but respond and transform in step with social, political and economic factors. Factors affecting access to rural and remote communities include underdeveloped infrastructure with physical topography, mountains, and poor roads creating difficulties for transportation (Magurunya, 2011). De Vrieze and Murapa (2012) point to the challenges posed by the variable standard and quality of communications in Zimbabwe, between different rural and remote areas and between those communities and the urban centres.

Researchers in Zimbabwe also have to contend with government legislation aimed at giving the state control over the gathering and dissemination of information. The Access to Information and Protection of Privacy Act (AIPPA) of 2002 is a legal instrument that enables the government to monitor and control the flow of information in the country. The AIPPA has exemptions that make it easy for the government of to refuse to release information on the grounds that such release would not be in the "public interest" (Republic of Zimbabwe, 2002b, sect. 9(4)).

The Public Order and Security Act (POSA) of 2002 seeks to curtail civil liberties and the freedoms of movement, expression and assembly (Republic of Zimbabwe, 2002a). For example, Part IV sets the procedure to be followed in order to be granted permission to hold public gatherings, whereby the organiser or organisers must notify the regulating authority of the intention to hold a public gathering (sect. 24). These POSA procedures and requirements can affect researchers' use of focus groups as data-gathering tools in public institutions.

\section{The research}

The aim of my data collection was to evaluate the performance of the PCICs. The key data generated pertained to why constituents visit PCICs, the PCICs' distance from constituents' homes, the PCICs' number of monthly visitors, the significance of PCICs' physical locations, and constituents' challenges in accessing parliamentary information from the PCICs.

All research ethical considerations were observed, and permission was granted to conduct the study by the Clerk of the Parliament of Zimbabwe. The study was based on theoretical assumptions of the interpretive paradigm, which is based on the notion that social reality is created and sustained through the subjective experience of people involved in communication (Creswell, 2003). This interpretive worldview suggests one can consider either a qualitative approach or an approach combining qualitative and quantitative methods (Mackenzie \& Knipe, 2006).

My research into the PCICs combined qualitative and quantitative instruments. Qualitative research is carried out to enhance understanding of individuals' cultures, beliefs and values, human experiences and situations, as well as to develop theories 
that describe these experiences (Holloway \& Galvin, 2016). This research approach emerged from the behavioral and social sciences as a method of understanding the unique, dynamic, and holistic nature of human beings (Creswell, 2014).

The core target groups were PCIC office assistants (OAs), constituents, and Members of Parliament (MPs). These target groups were identified because they were thought to be appropriate in shedding light on the operation of PCICs in disseminating Parliamentary information to constituents.

PCIC OAs keep diaries of events for MP programmes, schedule meetings, and serve the public and visitors to the PCIC. Since they are locals, OAs have a good understanding of local communities and cultures. Constituents were also targeted as citizens residing in a legislative constituency who are the intended beneficiaries of parliamentary information. MPs were included in the study as they are the political leaders in constituencies and represent their respective constituents in Parliament. Data were also collected from the Parliamentary Programme Coordinator, the Clerk of Parliament, and some officers of Parliament.

A mixed-methods research approach (Ngulube, 2010) was used in this study because it allowed for convergent analysis of both quantitative and qualitative data as advised by Creswell (2009). Questionnaires, often accompanied by interviews/ discussions related to the questionnaire questions, were used to collect data from OAs, constituents, and MPs. The questionnaire was completed by 15 out of the 25 targeted OAs, 255 out of the 625 targeted constituents, and 20 out of the 25 targeted MPs. In-depth interviews were used to get data from the Parliamentary Programme Coordinator, the Clerk, and Parliamentary officers.

The study also used the direct observation method, as I made note of my own observations when I visited the PCICs. This allowed me to gain and document insights into elements such as constituents' behaviour at the PCICs, staff attitudes towards visiting constituents, the Centres' accessibility to constituents, the main activities taking place at the Centres, and the behaviours of survey and interview respondents. This method was used to complement the information gathered through the questionnaires and interviews.

Document analysis was also used, via scrutiny of OAs' reports, Parliamentary reports on its reform processes, and Parliamentary administration reports.

Having collected the data, quantitative data from questionnaires and interviews were analysed using the Statistical Package for the Social Sciences (SPSS), while qualitative data were analysed according via thematic codes. While questionnaires can provide evidence of patterns amongst large populations, qualitative interview data often gather more in-depth insights on participant attitudes, thoughts, and 
actions (Harris \& Brown, 2010). Mixed-methods research treats the paradigmatic differences between qualitative and quantitative methods as complementary, not incompatible (Day et al., 2008).

Purposive sampling was used to select the provinces during the first stage of selecting the sample. This decision was based on opinions about the districts which are typical or representative in some sense or context; for instance, most Mashonaland districts are typically dominated by Zimbabwe African National Union-Patriotic Front (ZANU-PF) supporters, while the metropolitan areas and Matabeleland Province are typically dominated by Movement for Democratic Change (MDC) supporters. Other districts are typically "swing" provinces, with a mix of ZANU-PF and MDC support and neither political party in strong-majority control.

The provinces were also stratified using other predominant characteristics, such as rural/urban and geographical population spread, and then a random sample of constituencies was selected in a variety of ways, chosen from each stratum in a proportionate way. Decisions on how many PCICs to sample in the selelectd provinces was based to some extent on the total number of registered voters in the province. The numbers of registered voters were obtained from the Zimbabwe Electoral Commission Report on the Delimitation Exercise for the 2008 Harmonised Elections (ZEC, 2008).

In determining the sample size for this study, I considered the availability of time and resources, and the extent of the need to provide valid and reliable data. As Denscombe reminds us (2003, p. 23), urban and rural populations often differ significantly from each other in many ways, such as types of employment, sources and amounts of income, and average household sizes.

The locations of of the 24 PCICs studied, which included a wide range of urban and rural settings, are shown in Table 1. 
Table 1: Locations of PCICs studied

\begin{tabular}{|c|c|}
\hline Province & PCIClocation \\
\hline Harare & $\begin{array}{c}\text { 1. Harare Central } \\
\text { 2. Mt. Pleasant } \\
\text { 3. Budiriro } \\
\text { 4. Glen View South } \\
\text { 5. Kambuzuma } \\
\text { 6. Mbare } \\
\text { 7. St. Mary's Chitungwiza }\end{array}$ \\
\hline Masvingo & $\begin{array}{l}\text { 8. Gutu North } \\
\text { 9. Gutu Central } \\
\text { 10. Masvingo Urban } \\
\text { 11. Bikita West } \\
\text { 12. Mwenezi East }\end{array}$ \\
\hline Mashonaland Central & $\begin{array}{l}\text { 13. Mazowe South } \\
\text { 14. Mazowe West } \\
\text { 15. Mt. Darwin West } \\
\text { 16. Mt. Darwin South }\end{array}$ \\
\hline Matabeleland South & $\begin{array}{l}\text { 17. Bulilima South } \\
\text { 18. Bulilima } \\
\text { 19. Umzingwane }\end{array}$ \\
\hline Manicaland & $\begin{array}{l}\text { 20. Mutare Central } \\
\text { 21. Makoni South } \\
\text { 22. Mutasa South } \\
\text { 23. Dangamvura-Chikanga } \\
\text { 24. Headlands }\end{array}$ \\
\hline
\end{tabular}

\section{Data collection challenges encountered}

It must be emphasised that the findings presented in this article are ancillary to the main focus of the research data collection. The main focus of the research was linkages between the PCICs and their constituents. The focus here in this article is on the difficulties encountered while collecting data on the PCICs.

The data collection challenges faced can be grouped as follows:

- low PCIC office assistant (OA) response rate;

- low constituent response rate;

- unreliable road access;

- unsuitable physical locations of PCICs, including politicised locations;

- political and legal restrictions; 
- time management and financial challenges; and

- religious and cultural barriers.

In the following sub-sections, each of these challenges is considered in turn.

\section{Low PCIC office assistant (OA) response rate}

As stated in Section 3 above, only 15 of the 25 OAs who received questionnaires responded: a $60 \%$ response rate. Masvingo, Mashonaland Central and Harare Provinces had four respondents each, amounting to provincial response-rates of $80 \%$, $100 \%$ and $57 \%$ respectively, while Manicaland had two responses (for a response rate of 40\%) and Matebeleland South had one response (a 33\% response rate), as shown below in Table 2 .

Table 2: OAs' questionnaire response rates by province

\begin{tabular}{|c|c|c|}
\hline Province & $\begin{array}{c}\text { No. of constituencies in the } \\
\text { province }\end{array}$ & $\begin{array}{c}\text { Response rate in the } \\
\text { province (\%) }\end{array}$ \\
Harare & 7 & 57 \\
Masvingo & 5 & 80 \\
Mashonaland Central & 4 & 100 \\
Matebeleland South & 3 & 33 \\
Manicaland & 5 & 40 \\
\hline
\end{tabular}

Selected OAs in some provinces had to get permission from the MP in order for them to respond, hence the low OA response rate could have been due to those OAs that did not get permission from the MP to respond.

\section{Low constituent response rate}

As stated in section 3 above, only 255 out of the 625 constituents who received questionnaires responded-a $40.8 \%$ response rate.

Table 3 shows the response-rate distribution in each of the five provinces where constituents were surveyed. Harare Province had 83 respondents, followed by Masvingo with 71, Mashonaland Central 48, Manicaland 42, and Matebeleland South 11. 
Table 3: Constituents' questionnaire response rates by province $(\mathrm{N}=255)$

\begin{tabular}{|c|c|c|}
\hline Province & No. of responses & $\begin{array}{c}\text { Response rate in the } \\
\text { province (\%) }\end{array}$ \\
Harare & 83 & 32.5 \\
Masvingo & 71 & 27.8 \\
Mashonaland Central & 48 & 18.8 \\
Matabeleland South & 11 & 4.3 \\
Manicaland & 42 & 16.5 \\
\hline
\end{tabular}

It was found, in collecting data from the people who did respond, that two of the key reasons for many constituents' reluctance to participate in the research were: (1) low levels of awareness of the objectives and functions of the PCICs, and (2) fear and mistrust of researchers. Where I did succeed in getting constituents to participate, it was often with the assistance of OAs.

\section{Unreliable road access}

It was found that a key barrier to accessing the PCICs was poor infrastructure. Visiting the rural and remote constituencies was a major challenge for the researcher. Most Zimbabwean rural areas' road networks are poor. Virtually impassable roads lead to what can be called "road bias". For example, in one remote constituency, progress was blocked by a damaged bridge.

The infrastructure barriers posed two key potential data collection problems. First, respondents in easily accessible areas do not provide an accurate representation of national realities including people in remote areas. Second, such respondents have had numerous contacts with researchers. They are a "convenient sample", so to speak, and hence are to some extent over-researched and, accordingly, tend to be sceptical or unfriendly towards researchers (as a result of false promises, or crises of expectations, emerging from interactions with previous researchers). Such respondents potentially undermine the reliability and validity of a study by providing superficial, insincere answers aimed at bringing the research interaction to a rapid conclusion.

\section{Unsuitable physical locations of PCICs, including politicised locations}

The physical locations of each PCIC studied had a direct bearing on my ability to collect data. Nearly half (47.4\%) of the PCICs studied were located at local government premises, and the second-largest number (37\%) were located on nongovernment, privately-owned premises. It was found that the PCICs located at privately-owned premises were mostly in constituencies loyal to the opposition MDC party-constituencies where, due to political conflict between the MDC and 
the ruling ZANU-PF party at the time of the establishment of the PCICs, the PCIC for that constituency, which had an MDC MP, was not able to obtain office space at the local government premises (because of national control of most government premises by the ruling ZANU-PF).

The location of PCICs in private premises meant that I would have needed to seek data collection permission from the owner, regardless of the fact that permission had already been granted from Parliament to collect data at PCICs.

Other challenges posed by the physical locations of individual PCICs were as follows:

Harare Central PCIC- located at Trafalgar Court, this PCIC was not visible at all to constituents, although it was in the central business district (CBD) of the capital city Harare. The billboard for the Centre was badly placed, and directions to the office from outside the building could not be found. Very few constituents were managing to visit the PCIC, and this compromised the number of constituent respondents at this PCIC.

Headlands PCIC - this PCIC was moved from Headlands constituency to the town of Rusape, ostensibly because Headlands people could not locate it. However, the new location, at the MP's house, was not an improvement, because respondents conceived of it as a partisan space and did not feel comfortable going there for PCIC matters.

Mount Darwin South PCIC-this PCIC was located close to an office of the Zimbabwe National Liberation War Veterans Association, which is aligned to the ZANU-PF party, and the OAs working at this PCIC had been instructed to report "strangers", and their reasons for visiting, to the Association office. Accordingly, distribution of the research questionnaires, and discussions related to the questionnaires, were held in the presence of a War Veterans Association representative. This posed a significant challenge to my research, as the respondents were clearly not able to express themselves freely in such conditions.

\section{Political and legal restrictions}

Zimbabwe's aforementioned Public Order and Security Act (POSA) of 2002 impacted access to information during the research. POSA restricts public gatherings, so the constituents could not feel free and secure to hold meetings at PCICs, for fear of victimisation by law enforcement agents. Accordingly, I had to forego using focus groups, because this would have required obtaining police clearance, a difficult and onerous task. The research was thus forced to rely almost entirely on questionnaires to get the views of constituents. 


\section{Time management and financial challenges}

In some constituencies, a second visit was required to collect completed questionnaires, due to delays in having them returned by OAs, constituents. and MPs. Many of these follow-up visits were caused by failure to meet MPs and OAs during the first appointments made with them, due in part to unreliable communication networks. Many of targeted MPs were, at the time of the research, participating in outreach activities linked to the new Constitution of 2013, making it difficult to get them to complete and submit the questionnaires. These second visits to constituencies, especially to remote ones, generated time management and financial challenges.

Work pressures also affected the time devoted to data collection, as there was need to balance my research with regular work activities.

\section{Religious and cultural barriers}

In some constituencies in Manicaland Province, respondents from Apostolic Church groups refused to complete questionnaires or be interviewed, and some women respondents in Manicaland refused to participate in the absence of their husbands. It became necessary to enlist the help of OAs to navigate these issues, as they were local people with strong linkages within the constituencies.

Another "cultural" barrier faced were the requests from some MPs to be financially compensated for their participation-even after explanation had been provided in detail about the purpose of the research and the MP in question had been shown the letter of consent for the research from the Clerk of the Parliament of Zimbabwe.

\section{Conclusions}

The data collection challenges outlined in this article, in the Zimbabwean context, provide lessons that can potentially be of value to other researchers working in developing-country contexts. Perhaps the most important lesson learned was that in order to carry out data collection successfully in rural Zimbabwe, the researcher has to have-or develop, or get access to via others—strong connections with people based in the local environments in which the data collection takes place.

In the case described in this article, it became necessary, in certain constituencies, to rely to a great extent on linkages possessed by the locally-embedded PCIC OAs. This lesson is, of course, not unique to rural, developing-world contexts. On-the ground connections are also undoubtedly essential for successful data collection in rural, developed-world contexts, and in urban contexts in both the developed and developing worlds. But as this article has demonstrated, the somewhat generic challenge of needing connections to the local people was exacerbated, during my research, by other challenges-e.g., unreliable roads, certain kinds of cultural barriers-that tend to be more pronounced in the developing world. And there were still other challenges-e.g., POSA restrictions on public gatherings, PCICs 
housed in the homes of opposition party MPs, the Veterans Asssociation monitoring comings and goings at a PCIC — that were unique to Zimbabwe's particular set of political realities.

\section{References}

Altshuld, J., \& Witkin, B. R. (2000). Transferring needs into solution strategies. Thousand Oaks, CA: Sage.

Bailey, C. A. (2007). A guide to qualitative field research. London: Sage. http://dx.doi.org/10.4135/9781412983204

Bulmer, M., \& Warwick, D. P. (1983). Social research in developing countries. London: John Wiley and Sons.

Busby, L.A.(2003). General data challenges facing the Caribbean in the context of sustainable development. Paper presented at "Using information for decision making on sustainable development: Issues and challenges for Caribbean SIDS" seminar, Saint Lucia, 27-28 May.

Cole, A. L., \& Knowles, J. G. (2001). Lives in context: The art of life history research. Oxford: Rowman and Littlefield.

Creswell, J. W. (2003). Research design: Qualitative and quantitative approaches. Thousand Oaks, CA: Sage.

Creswell, J. W. (2009). Research design: Qualitative, quantitative, and mixed methods approaches (3rd ed.). Thousand Oaks, CA: Sage.

Creswell, J. W. (2014). Research design: Qualitative, quantitative and mixed methods approaches (4th ed.). Thousand Oaks, CA: Sage.

Davies, M. B., \& Hughes, N. (2014). Doing a successful research project: Using qualitative or quantitative methods. London: Palgrave Macmillan.

Day, C., Sammons, P., \& Gu, Q. (2008). Combining qualitative and quantitative methods in research on teachers' lives, work, and effectiveness: From integration to synergy. Educational Researcher, 37(6), 330-342.

Dearnley, C. (2005). A reflection on the use of semi-structured interviews. Nurse Researcher, 13(1), 19-28.

Denscombe, M. (2003). The good research guide (2nd ed.). Buckingham, UK: Open University Press.

De Vrieze, F., \& Murapa, R. (2012). Evaluation of the UNDP parliamentary support project in Zimbabwe and recommendations: Final evaluation report. For the UN Development Programme.

Elahi, A. (2008). Challenges of data collection in developing countries - the Pakistani experience as a way forward. Statistical Journal of the IAOS, 25 (1,2), 11-17.

Feltoe, G., \& Maguranyanga, B. (2015). Where do religion and the law in Zimbabwe meet? An analysis of apostolic religion, Doctrine and practices related to maternal and newborn child health in Zimbabwe. UNICEF. Retrieved from https://www.unicef. org/zimbabwe/Legal-Review-of-Apostolic-Religion 
Gill, P., Stewart, K., Treasure, E., \& Chadwick, B. (2008). Methods of data collection in qualitative research: Interviews and focus groups. British Dental Journal, 204, 291295. https://doi.org/10.1038/bdj.2008.192

Harris, L. R., \& Brown, G. T. L. (2010). Mixing interview and questionnaire methods: Practical problems in aligning data. Practical Assessment, Research and Evaluation, 15(1), 1-19. Retrieved from https://pareonline.net/pdf/v15n1.pdf

Holloway, I., \& Galvin, K. (2016). Qualitative research in nursing and healthcare. London: John Wiley and Sons.

Hudson, P. (2007). Parliamentary institutes. Ostrava, Czech Republic: University of Ostrava.

Lutabingwa, J., \& Nethonzhe, T. (2006). Ethical issues in social research. Journal of Public Administration, 41, 694-702.

Machingura, F. (2014). The martyring of people over radical beliefs: A critical look at the Johane Marange Apostolic Church's perception of education and health. In E. Chitando, M. R. Gunda, \& J. Kugler, J. (Eds.), Multiplying in the spirit: African initiated churches in Zimbabwe (pp. 175-198). Bamberg, Germany: University of Bamberg Press.

Maguranya, B. (2011). Apostolic religion, health and utilization of maternal and child health services in Zimbabwe. Harare: Collaborating Center for Operational Research and Evaluation and UNICEF. Retrieved from https://www.unicef.org/zimbabwe/ZIM resources apastolicreligion.pdf

Makumbe, J. (1996, March 21-25). Participatory development: The case of Zimbabwe. Human Rights Bulletin.

Mapuva, J. (2007). An examination of the role played by selected civil society organisations in promoting democracy in Zimbabwe, 1980-2007. Masters' thesis, University of the Western Cape, Cape Town.

Mandelbaum, A. G. (2011). Strengthening parliamentary accountability, citizen engagement and access to information: A global survey of parliamentary monitoring organizations. Washington, DC: National Democratic Institute (NDI) and World Bank Institute (WBI). Retrieved from https://www.ndi.org/sites/default/files/governanceparliamentary-monitoring-organizations-survey-september-2011.pdf

Mostert, B. J. (2004). Parliamentary information sources, systems and services in South Africa and the role of parliamentary libraries in information provision. $\mathrm{PhD}$ thesis, University of Zululand, KwaDlangezwa, South Africa.

National Research Council (NRC). (2014). Conducting research in developing countries. In Culture matters: International research collaboration in a changing world (Summary of a workshop). Washington, DC: The National Acadamies Press.

Ngulube, P. (2010). Mapping mixed methods research in library and information science journals in Sub-Saharan Africa 2004-2008. International Information E Library Review, 42(4), 252-261. https://doi.org/10.1080/10572317.2010.10762870

Peersman, G. (2014). Overview: Data collection and analysis methods in impact evaluation. Methodological Briefs: Impact Evaluation. UNICEF Office of Research. Retrieved from http://www.unicef-irc.org/KM/IE/

Republic of Zimbabwe. (2002a). Public Order and Security Act (POSA) (No. 1) of 2002. 
Republic of Zimbabwe. (2002b). Access to Information and Protection of Privacy Act (AIPPA) (No. 5) of 2002.

Republic of Zimbabwe. (2013). Constitution of Zimbabwe Amendment Act (No. 20) of 2013.

Silverman, D. (2009). Evaluating qualitative research (3rd ed.). Thousand Oaks, CA: Sage.

UN Economic, Scientific and Cultural Organisation (UNESCO). (2009). The 2009 UNESCO framework for cultural statistics. Montreal: UNESCO Institute for Statistics.

Zimbabwe Electoral Commission (ZEC). (2008). Report on the delimitation exercise for the 2008 harmonised elections. Harare. 